https://dx.doi.org/10.4314/ijs.v19i1.10

Ife Journal of Science vol. 19, no. 1 (2017)

\title{
PREPARATION AND CHARACTERIZATION OF SYNTHESIZED GOETHITE AND GOETHITE-DATE PALM SEEDS CHARCOAL COMPOSITE
}

\author{
Abdus-Salam N. and Ikudayisi V. A.* \\ Department of Chemistry, University of Ilorin, Ilorin, Nigeria \\ *Corresponding author: ikudayisiabiola@gmail.com \\ (Received: 1st November, 2016; Accepted: 13th June, 2017)
}

\section{ABSTRACT}

\begin{abstract}
In this study, goethite $(\mathrm{FeOOH})$ which is an iron oxy-hydroxide was synthesized within a short time with iron (II) chloride and sodium hydrogen carbonate precursors through air oxidation method. Date-palm (Phoenix dactylifera) seeds charcoal was also prepared and used as composite with the goethite. Physico-chemical properties such as the $\mathrm{pH}$, moisture content, percentage yield, bulk density and $\mathrm{pH}_{\mathrm{pzc}}$ were investigated. Instrumental characterization such as Fourier Transform Infrared (FTIR) for the surface functional groups, Scanning electron microscopy (SEM) for the shapes and morphology of both samples, X-Ray Fluorescence (XRF) to obtain the elemental composition, BET surface area determination and particle nano-sizer to determine the size of the particles were carried out. The results obtained showed that $\mathrm{pH}_{\mathrm{pzc}}$ values were 8 and 7 for goethite and composite respectively. The main surface functional group from FTIR and major element obtained from XRF in both samples is the $\mathrm{OH}$ group and iron $(\mathrm{Fe})$ respectively. The SEM results for goethite and the composite particles showed high porosity in their structure which enables them to bind easily with other materials. BET revealed that the surface area of the goethite and the composite is 797.662 and $329.866 \mathrm{~m}^{2} / \mathrm{g}$ respectively. The nano-sizer also revealed a near nano-size for the synthesized goethite with particle size of about $172-173 \mathrm{~nm}$. Based on the results obtained, the synthesized goethite and the prepared composite will find applications in various analytical and chemical procedures.
\end{abstract}

Keywords: Iron oxy-hydroxide, Goethite, Date-palm seeds, Particle nano-sizer, BET.

\section{INTRODUCTION}

Composites are materials made from two or more constituent materials with significantly different physical or chemical properties, that when combined, produce material with characteristics different from the individual components. The individual components remain separate and distinct within the finished structure. The overall structure produced is usually better than the individual components (Abdullahi et al., 2014).

According to the literatures, there are about 14 species of iron oxides, ten of which have been reported to occur in nature, the most abundant being goethite $(\alpha-\mathrm{FeOOH})$, hematite $\left(\alpha-\mathrm{Fe}_{2} \mathrm{O}\right)$ and magnetite $(\mathrm{Fe}, \mathrm{O})$, followed by ferrihydrite $\left[\mathrm{Fe}_{10} \mathrm{O}_{14}(\mathrm{OH})_{2}\right]$ (Guo and Barnard, 2013), maghemite $\left(\gamma-\mathrm{Fe}_{2} \mathrm{O}\right)$ and lepidocrocite $(\gamma$ $\mathrm{FeOOH})$. Iron oxides are generally known to be responsible for the movement and behaviour of numerous chemical species in soils, rocks and aquatic environments through adsorption processes (Adegoke et al., 2013) and other chemical reactions, particularly onto goethite and ferrihydrite (Villalobos and Antelo, 2011) or through adsorption followed by reduction mechanisms as is the case of susceptible species on magnetite (Villacís-García et al., 2015). Goethite $(\mathrm{FeO}(\mathrm{OH})$ or $\alpha-\mathrm{FeOOH})$ named after the German polymath and poet Johann Wolfgang von Goethe (1749-1832). It is an iron bearing hydroxide or oxy-hydroxide mineral and is found in soil and other low-temperature environments, with the surface functional group being the hydroxyl group which can bind strongly to both organic and inorganic ligands (Abdus-Salam and Adekola, 2005). Goethite particles show high specific surface areas and strong affinities for surface binding of oxyanions and heavy metals (Fendorf et al., 1997). Goethite has been well known since ancient times for its use as a pigment (brown ochre) (Van der Zee et al., 2003). It is the main component of rust and bog iron ore. Its specific gravity varies from 3.3 to 4.3 , with its colour ranging from yellowish to reddish to dark brown or black. Goethite is found to be soluble in hydrochloric acid and is weakly magnetic. Fine goethite specimens are rare and therefore are valued collectibles and some varieties are cut and polished for jewelry making. Goethite particles are said to often form through the weathering of other iron-rich minerals or rocks, and thus is a 
common component of soils. The formation of goethite is marked by the oxidation state change of $\mathrm{Fe}^{2+}$ to $\mathrm{Fe}^{3+}$, which allows for goethite to exist at surface conditions (Van der Zee et al., 2003, Abdus-Salam and Adekola, 2005).

The date palm (Phoenix dactylifera), a tropical and subtropical tree, belonging to the family Palmae (Arecaceae) is one of mankind's oldest cultivated plant (Chandrasekaran and Bakhali, 2012). The whole date fruits are traditionally used to prepare a wide range of products such as date juice concentrates (spread, syrup and liquid sugar), fermented date products (wine, alcohol, vinegar, and organic acids) and date pastes for different uses (e.g. bakery and confectionary) besides their direct consumption. Date processing industries manufacture a variety of date products such as date-paste, date-syrup, date dip, date-honey, datejam and date-vinegar. Date pectin, dietary fibre and syrup are some of the date substances which find a plethora of applications as a thickener or gelling agent in processed foods, such as confectionery products, jams, table jellies, soft cheeses, yoghurts e. t. c. Palms are also widely used in landscaping for their exotic appearance, making them one of the most economically important plants (Chandrasekaran and Bakhali, 2012).

Date palm seeds otherwise called date pits, pips, kernels or stones are considered as a waste byproduct and form around 6-10\% of the fruit weight (Arshad et al, 2014). Experiments conducted show that date seeds contain approximately $55-65 \%$ of carbohydrates. In view of this, high-grade activated carbon can be obtained from date seeds due to their high carbon content (Arshad et al, 2014). Date seeds are usually grounded for animals feed such as cattle, sheep, camel and poultry (Al-Haddabi et al., 2015). This research work is aimed at exploiting the need to combine the unique properties of goethite and date palm seeds charcoal in composite preparation in order to achieve a different novel material which can find applications in many chemical, environmental, biological and technological procedures.

\section{EXPERIMENTAL}

\section{Materials}

All reagents and chemicals that were used in the course of this study were analytical grade reagents which were purchased from reputable retail outlets. These include ortho phosphoric acid, ferrous chloride (Sigma Aldrich), ethanol (Sigma Aldrich), and sodium hydrogen carbonate (Sigma Aldrich). De-ionized water was used where applicable especially during the preparation of standard solutions. All pieces of plastics used during the experiments were thoroughly washed and rinsed. All glass wares were washed with deionized water and dried in hot air oven before use.

\section{Synthesis of Goethite}

Goethite $(\alpha-\mathrm{FeOOH})$ particles were synthesized by dissolving $10 \mathrm{~g}$ of $\mathrm{FeCl}_{2} \cdot 4 \mathrm{H}_{2} \mathrm{O}$ in $1000 \mathrm{ml}$ of deionized water and then $110 \mathrm{ml}$ of $1 \mathrm{M} \mathrm{NaHCO}_{3}$ was added to the solution at room temperature. The yellow deposits, goethite particles, were formed after air-oxidation of the solution for approximately $25 \mathrm{~min}$. The goethite particles were then separated from the solution by filtering and washing with ethanol and de-ionized water several times. The particles were then oven dried at $70^{\circ} \mathrm{C}$ for about $1 \mathrm{hr}$ and kept for further use (Lee $e t$ al., 2004).

\section{Preparation of Date palm seeds charcoal}

Date palm fruits were purchased from Tanke area in Ilorin, Kwara State, Nigeria. The fruits were removed and the seeds gathered. The date seeds were washed with hot de-ionized water severally to remove impurities (Ahmed et al., 2013), after which, they were dried in the oven at $105 \pm 5^{\circ} \mathrm{C}$ overnight to remove all the moisture. The seeds were crushed with hammer and then blended using an electric blender to the desired particle sizes which were later separated using sieve shaker to determine the sizes.

The Date palm seed powder obtained was weighed into a porcelain crucible and then taken to the muffle furnace, which was heated to a temperature of $500{ }^{\circ} \mathrm{C}$ and allowed to stay for approximately $1 \mathrm{hr}$, the charcoal obtained was removed and then transferred into a desiccator to cool, the charcoal was weighed to determine the percentage yield and then kept in an air tight container for further use. 


\section{Preparation of Goethite-Date palm seeds charcoal composite}

A slightly modified Lee $e t a l$. (2004) procedure for the synthesis of Goethite $(\alpha-\mathrm{FeOOH})$ particlesDate palm seeds activated carbon composite as described above was adapted. This involved dissolution of $1 \mathrm{~g}$ of $\mathrm{FeCl}_{2} \cdot 4 \mathrm{H}_{2} \mathrm{O}$ in $100 \mathrm{ml}$ of deionized water and then $11 \mathrm{ml}$ of $1 \mathrm{M} \mathrm{NaHCO}_{3}$ was added to the solution at room temperature, after which an equal weighted amount of the activated carbon was added in 1:1 impregnation ratio and stirred. Goethite - date seeds activated carbon composite (COM) was prepared after airoxidation of the solution for approximately 25 min. The composite was then separated from the solution through filtering and washing with ethanol and de-ionized water several times and oven dried at $70^{\circ} \mathrm{C}$ for about $1 \mathrm{hr}$ and kept in an air tight container for use.

\section{Physico-chemical Characterization methods}

The synthesized samples were characterized by determining some physico-chemical parameters such as $\mathrm{pH}$, bulk density, moisture content, percentage yield and $\mathrm{pH}_{\mathrm{pzc}}$.

The $\mathrm{pH}$ of the goethite and composite samples were determined by weighing $4 \mathrm{~g}$ of each of the sample into $250 \mathrm{ml}$ flask, $100 \mathrm{ml}$ of boiled distilled water was added and the contents was covered and allowed to boil on a hot plate for $5 \mathrm{~min}$. A thermometer was inserted and set aside for a few moments to allow the bulk of the sample particles to settle, the supernatant liquid was poured before it cools to $60^{\circ} \mathrm{C}$, the decanted portion was cooled to room temperature and the $\mathrm{pH}$ reading was then taken (Abdus-Salam and Buhari, 2014).The bulk density of the samples was also determined by tapping method (Yoshiguki and Yukata, 2003). The $\mathrm{pH}$ point of zero charge of the samples was determined by using $\mathrm{pH}$ drift method (AbdusSalam and Adekola, 2005).

\section{Instrumental Characterization}

The synthesized goethite particles and the composite were further characterized using Fourier Transform Infrared (SHIMADZU series) in order to reveal the surface functional groups, Scanning Electron microcopy to determine the morphology and shapes of the particles, X-Ray Fluorescence to obtain the elemental composition, Bruanuer Emmett Teller surface area determination (Nova Station C BET instrument) and Particle nano-sizer (Malvern instrument) to determine the particle sizes and size composition.

\section{RESULTS and DISCUSSION \\ Physico-chemical Characteristics}

The goethite particles synthesized is fine in texture and insoluble in water but readily soluble in acids. It is weakly magnetic and leaves a brown stain on fabrics (Van der Zee et al., 2003). Other results of the physico-chemical characteristics of both samples are presented in table 1.

Table 1: Physico-chemical characteristics of the goethite and goethite-date palm seeds charcoal composite

\section{Physico-chemical characteristics}

\begin{tabular}{ccccccc}
\hline Samples & Colour & Texture & $\mathrm{pH}$ & $\mathrm{pH}_{\mathrm{pzc}}$ & $\begin{array}{c}\text { Bulk } \\
\text { Density }\end{array}$ & $\begin{array}{c}\text { Percentage } \\
\text { Yield (\%) }\end{array}$ \\
\hline Goethite (GT) & $\begin{array}{c}\text { Golden- } \\
\text { brown }\end{array}$ & Fine & 7.8 & 8.0 & 0.86 & 25 \\
Composite (COM) & $\begin{array}{c}\text { Dark- } \\
\text { brown }\end{array}$ & Fine & 7.6 & 7.0 & 0.74 & 92 \\
\hline
\end{tabular}


The colour of the goethite was found to be golden brown as reported by other researchers (Van der Zee., 2003). The colour of the composite changed to dark brown because of the combination of goethite with the date-palm seeds charcoal which is black in colour. The $\mathrm{pH}$ and $\mathrm{pH}_{\mathrm{pzc}}$ of the goethite and the composite samples were slightly basic due to the presence of $\mathrm{OH}^{-}$groups on both samples. The point of zero charge of a material facilitates the choice of an adsorbent for removal of certain solutes from waste water; it also makes it possible to predict the $\mathrm{pH}$ effect on the phenomena and processes involving adsorption (Adegoke et al., 2013) and it is in agreement with the value obtained in the literature (Abdus-Salam and Adekola, 2005). The goethite sample which was synthesized by air oxidation method has 25\% yield and the composite, $92 \%$ yield as little was lost in the preparation of the composite. The goethite was found to be denser than the composite due to the heavy presence of high density iron metal in the iron oxide $(\mathrm{FeOOH})$.

\subsection{Fourier Transform Infrared (FTIR)}

FTIR is a characterization method which is used to identify and elucidate the surface functional groups of sample material. The results of the FTIR analysis of the date-palm seeds charcoal, goethite and the composite are shown in the figures (1a and $1 \mathrm{~b})$ with their vibrational peaks shown in table 2 .

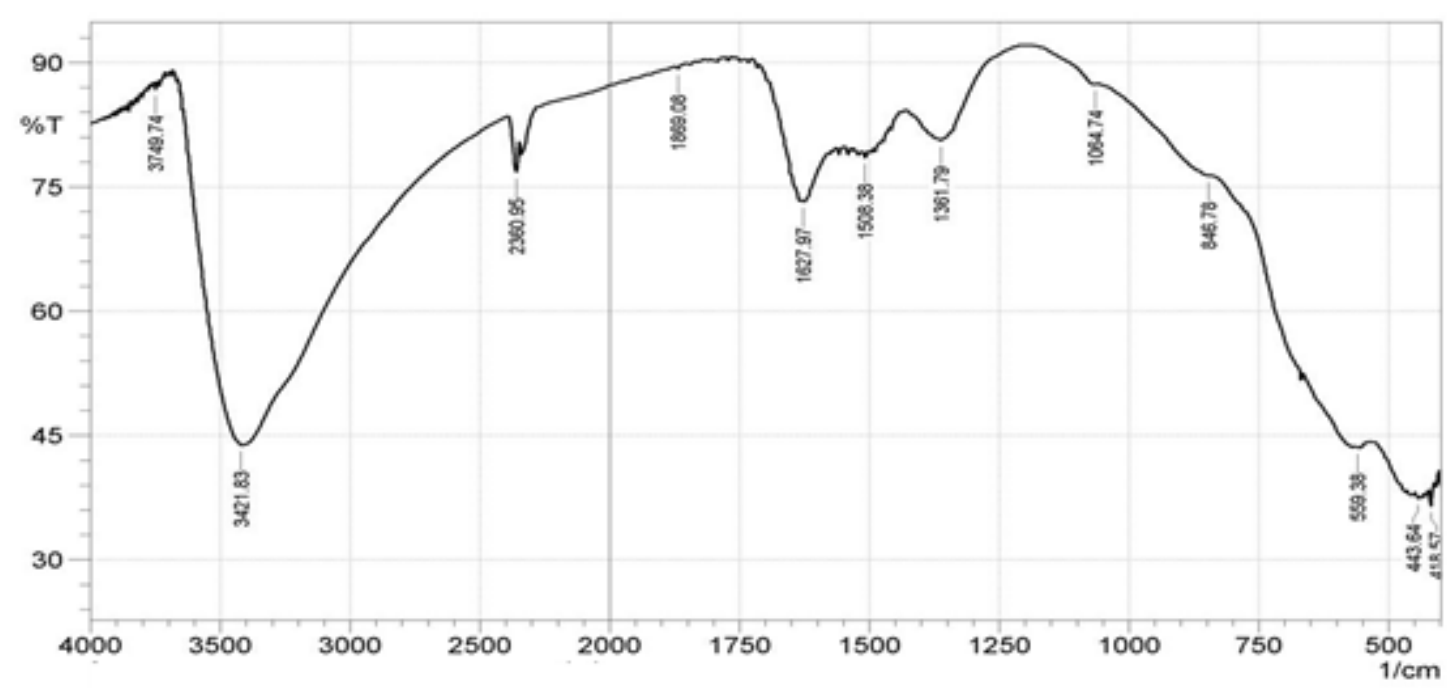

Fig 1a: FTIR Spectrum of the Goethite particles

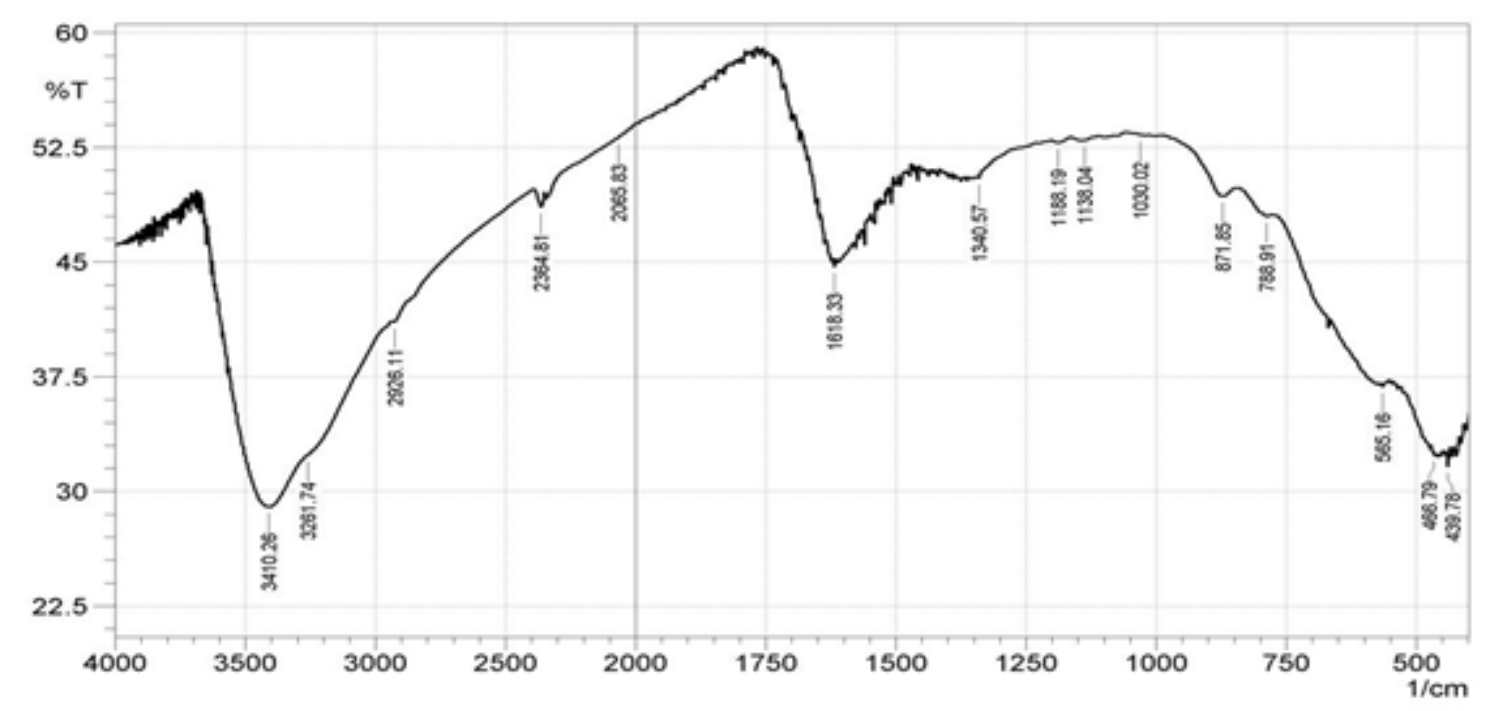

Fig 1b: FTIR Spectrum of the Composite 
Table 2: Summary of the Infrared frequencies $\left(\mathrm{cm}^{-1}\right)$ of the samples

\begin{tabular}{ccc}
\hline $\begin{array}{c}\text { Goethite frequencies } \\
\left(\mathrm{cm}^{-1}\right)\end{array}$ & $\begin{array}{c}\text { Composite } \\
\text { frequencies }\left(\mathrm{cm}^{-1}\right)\end{array}$ & Assignment \\
\hline 3421.83 & 3410.26 & O-H stretching vibrations \\
- & 2926.11 & $\begin{array}{c}\text { C-H stretching vibrations (due to } \\
\text { date palm seeds charcoal) }\end{array}$ \\
1627.97 & 1618.33 & H-O-H bending vibrations \\
559.38 & 565.13 & Fe-O stretching vibrations \\
418.57 & 439.78 & Fe-O bending vibrations \\
\hline
\end{tabular}

\section{Scanning Electron microscopy (SEM)}

SEM analysis is usually carried out to determine the particle size, morphology and shape of the adsorbents particles (Harikumar et al., 2013).
Figures $2 \mathrm{a}$ and $2 \mathrm{~b}$ showed clear SEM micrographs of the goethite and the composite samples in 500x magnification.

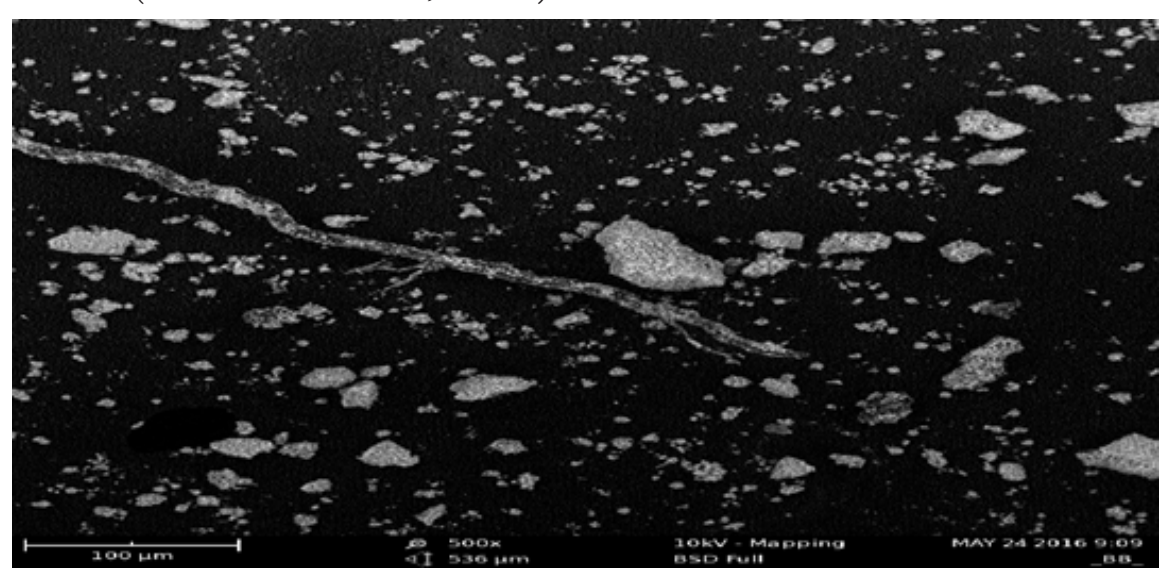

Fig. 2a: SEM micrograph of goethite particles (magnification x 500x)

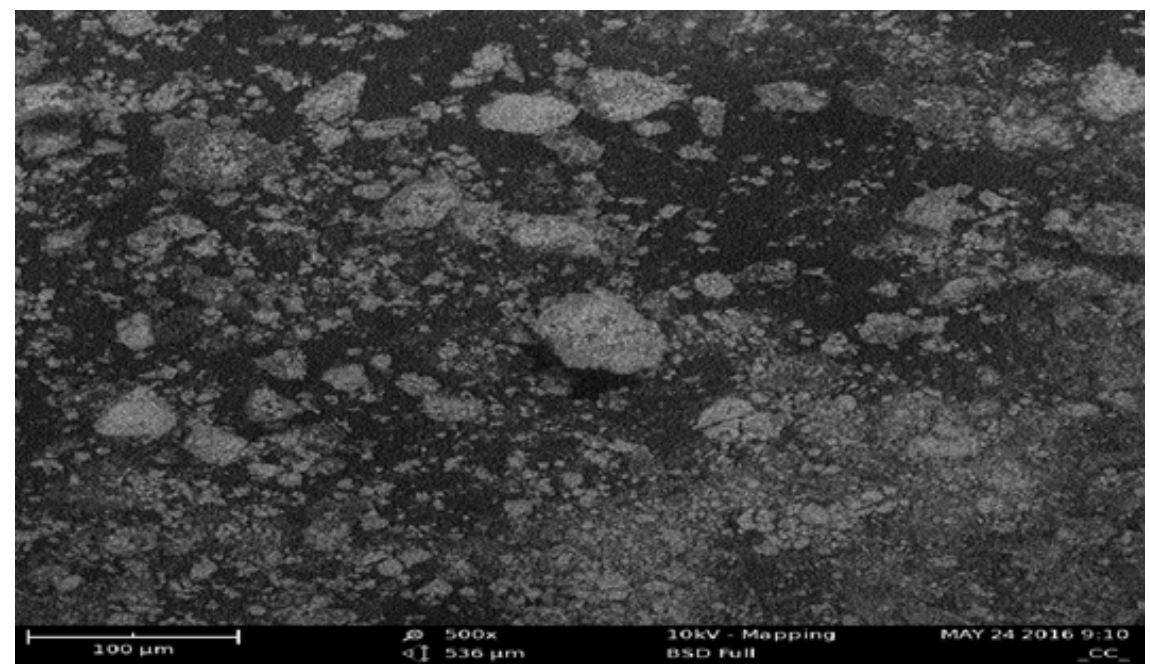

Fig. 2b: SEM micrograph of the composite particles (magnification x 500x) 
The goethite (GT) particles showed dense iron oxide which were found to be spherical in shape and tends to agglomerate, smaller and more homogenous particles were also found in goethite than the composite. The surface of the goethite particles showed large pores (high porosity) (Lee et al., 2004) for binding with other materials.

In a similar manner, the composite particles of the date palm seeds and goethite contained dense iron oxide, spherical in shape, heterogeneous and porous surface but the size of pores was found to be reduced as compared to the goethite (Falah et al., 2015), this is due to the pores of the goethite particles being occupied by the date palm seeds charcoal during the formation of the composite which gives it some distinct characteristics different from both the goethite and the charcoala major peculiarity and uniqueness of composites (Abdullahi et al., 2014).

\section{X-Ray Fluorescence}

$\mathrm{X}$-ray fluorescence analysis is used to determine the elemental composition of a material which is mostly metals. Table 3 is the XRF results of the elemental compositions of goethite and COM.

The major component of the synthesized goethite is iron with $66.4009 \%$ Fe while cobalt, lead and tin occurred as minor elements and others as trace elements. The major component of the composite is Fe with $64.4557 \% \mathrm{Fe}$. These values of iron are in close agreement with the value of 63 $-64 \%$ reported in the literatures (Mutembei et al., 2014). The minor elements are potassium, cobalt, lead, tin and antimony while other elements occurred in the trace level. The minor and trace elements in the synthesized goethite and COM, constituted $1.3024 \%$ and $1.5151 \%$ respectively, and were impurities in the precursors used for the synthesis.

Table 3: Elemental composition of the synthesized goethite

\begin{tabular}{cccc}
\hline \multicolumn{2}{c}{ Goethite } & \multicolumn{2}{c}{ Composite } \\
\hline Element & Content $(\%)$ & Element & Content $(\%)$ \\
\hline $\mathrm{Mg}$ & 0.0182 & $\mathrm{Mg}$ & 0.0547 \\
$\mathrm{P}$ & 0.0032 & $\mathrm{P}$ & 0.0079 \\
$\mathrm{Ca}$ & 0.0902 & $\mathrm{Ca}$ & 0.0773 \\
$\mathrm{~V}$ & 0.0210 & $\mathrm{~V}$ & 0.0188 \\
$\mathrm{Cr}$ & 0.0619 & $\mathrm{Cr}$ & 0.0551 \\
$\mathrm{Mn}$ & 0.0823 & $\mathrm{Mn}$ & 0.0776 \\
$\mathrm{Co}$ & 0.4024 & $\mathrm{Co}$ & 0.3804 \\
$\mathrm{Fe}$ & 66.4009 & $\mathrm{Fe}$ & 64.4557 \\
$\mathrm{Ni}$ & 0.0724 & $\mathrm{Ni}$ & 0.0759 \\
$\mathrm{Cu}$ & 0.0196 & $\mathrm{Cu}$ & 0.0210 \\
$\mathrm{Zn}$ & 0.0361 & $\mathrm{Zn}$ & 0.0358 \\
$\mathrm{~Pb}$ & 0.2151 & $\mathrm{~Pb}$ & 0.1854 \\
$\mathrm{Rb}$ & 0.0077 & $\mathrm{Rb}$ & 0.0064 \\
$\mathrm{Mo}$ & 0.0849 & $\mathrm{Mo}$ & 0.0718 \\
$\mathrm{Sn}$ & 0.1202 & $\mathrm{Sn}$ & 0.1991 \\
$\mathrm{Sb}$ & 0.0672 & $\mathrm{Sb}$ & 0.1324 \\
- & - & $\mathrm{Nb}$ & 0.0005 \\
- & - & $\mathrm{Cd}$ & 0.0007 \\
- & - & $\mathrm{K}$ & 0.1123 \\
- & - & $\mathrm{Al}$ & 0.0020 \\
\hline
\end{tabular}




\section{Bruanuer Emmett Teller surface area}

The surface areas (SA) of the goethite and the composite were determined by the BET adsorption method using Nova Station C BET instrument and nitrogen as the adsorbate. From the data obtained, the surface area of the goethite was found to be $797.662 \mathrm{~m}^{2} / \mathrm{g}$ and that of the composite to be $329.866 \mathrm{~m}^{2} / \mathrm{g}$. The surface area values obtained from the BET analysis of the goethite particles were far greater than the values obtained in the literatures (Villacis-Garcia et al., 2015; Lakshmipathiraj, 2006). This result made the synthesized goethite to fall into the category of 'ideal crystal' of goethite (SSA $>80 \mathrm{~m}^{2} / \mathrm{g}$, in which SSA (specific surface area) is the total of external surface area and internal surface area of a material) (Villalobos and Perez-Gallegos, 2008). The large difference in the BET surface areas, pore size and pore volume of the goethite and the composite particles is an indication that the synthesized goethite particles are smaller in size than the composite particles and part of the total surface area and pore volume of the goethite were covered with date palm charcoal. This is due to the combination of the goethite with the larger particles of the date palm seeds charcoal, leading to the reduced surface area in which the greater the particle size, the lesser the surface area (VillacisGarcia et al., 2015; Maji et al., 2007).

\section{Particle Nano-sizer}

The sizes of the synthesized goethite particles were determined by using the Malvern particle nano-sizer and the results obtained are presented in figures $4 \mathrm{a}$ and $4 \mathrm{~b}$ for size distributions by intensities and volume respectively. From the figure, it was observed that the synthesized goethite contained near nano-sized particle with the average range within the size of $172-173 \mathrm{~nm}$. The results also revealed that the goethite sample is coloured (as expected) and fluorescence on exposure to electromagnetic radiation. Therefore, according to the definition of a nano-sized material being in the range of $1-100 \mathrm{~nm}$, it can be concluded that the synthesized goethite is not a nano- material but fine particle with sizes that are near nano-size upper limit (172 nm-173 nm).

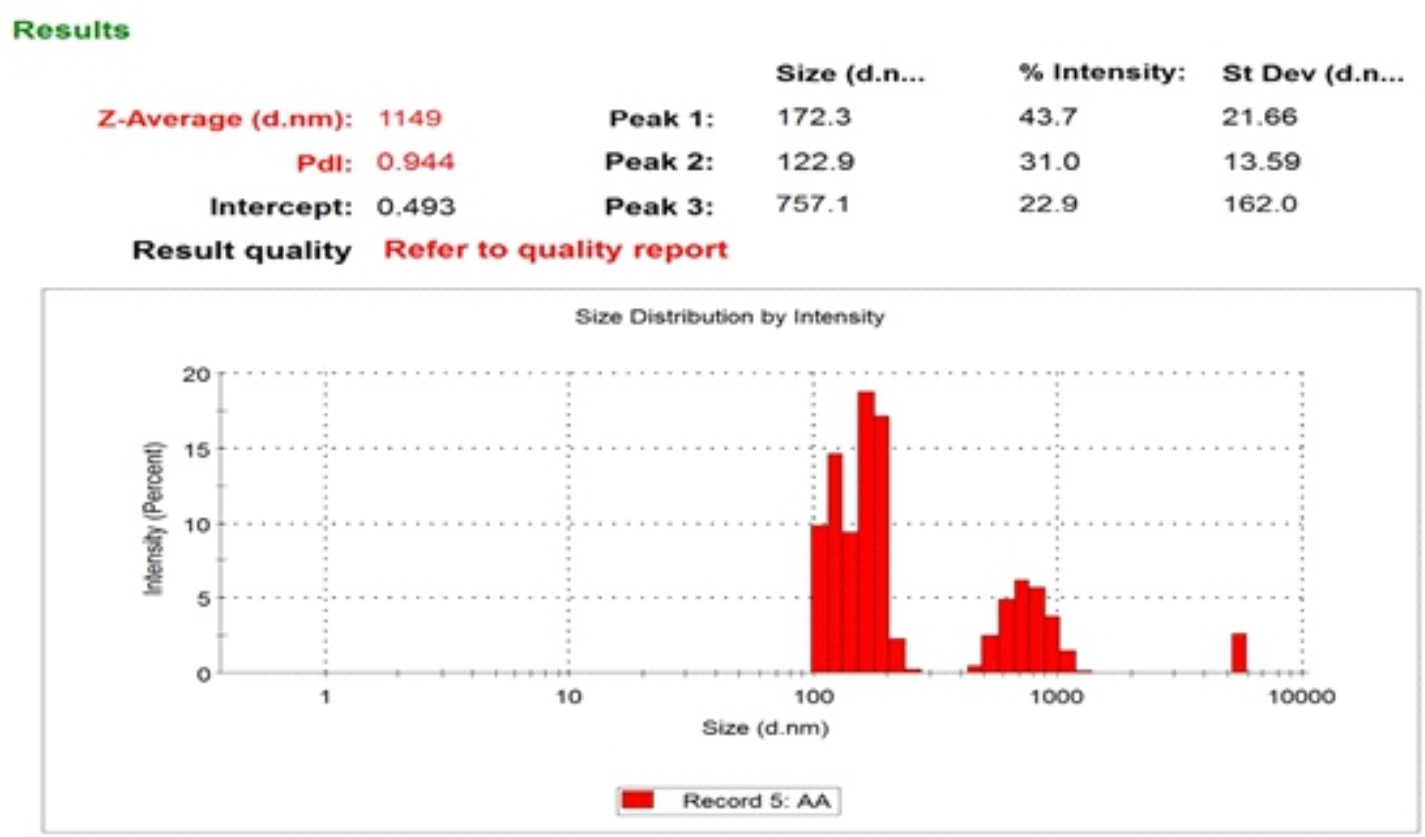

Fig. 4a: The size distribution of the goethite particles by intensity 


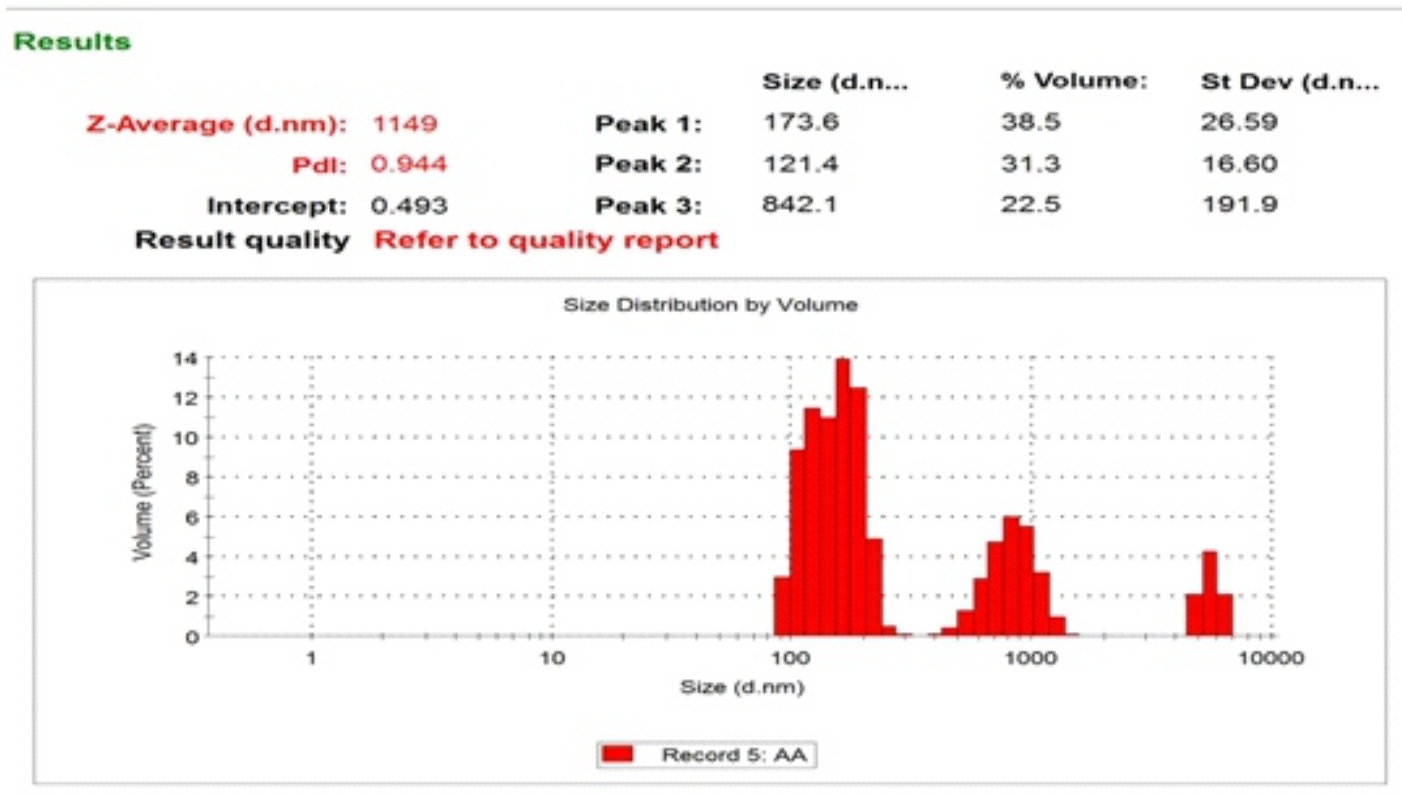

Fig. 4b: The size distribution of the goethite particles by volume

\section{CONCLUSION}

Goethite and its composite with date palm seeds charcoal were prepared and characterized by some physico-chemical parameters- such as the bulk density, percentage yield, $\mathrm{pH}$, moisture content and the $\mathrm{pH}_{\mathrm{pzc}}$. The instrumental techniques used were FTIR, XRF, SEM, BET and particle nanosizer. The FTIR and XRF results showed that the major functional group and element on both samples are $\mathrm{OH}^{-}$and iron $(\mathrm{Fe})$ due to the chemical structure of the goethite $(\mathrm{FeOOH})$. The SEM analysis revealed that the goethite sample is homogenous and spherical in shape while that of the composite is heterogeneous with different shapes observed due to the combination of two different materials. In addition to this, high porosity was observed with both samples. The surface areas of goethite and composite were found to be $797.662 \mathrm{~m}^{2} / \mathrm{g}$ and $329.866 \mathrm{~m}^{2} / \mathrm{g}$ respectively. The larger surface observed with the goethite categorized the sample to be an ideal crystal group of goethite.

Furthermore, the size of the goethite particles were about $172-173 \mathrm{~nm}$ as revealed by the nanosizer analysis. These characterization analyses made on goethite and the novel composite of goethite and date palm seeds charcoal will help both samples to find applications in various analytical procedures such as ion exchange, chromatographic methods and adsorption processes to mention but a few.

\section{REFERENCES}

Abdullahi, D., Okezie, Q. and Mohammed, A. B. 2014. Preparationand Properties of Date seed/Natural Rubber Composites. International Journal of Emerging Technology and Advanced Engineering 4(9): 152-156.

Abdus-Salam, N. and Adekola, F. A. 2005. The influence of $\mathrm{pH}$ and Adsorbent Concentration on Adsorption of Lead and Zinc on a Natural Goethite. African Journal of Science and Technology (AJST) 6(2): 55-66.

Abdus-Salam, N. and Buhari, M. 2014. Adsorption of Alizarin and Fluorescein Dyes on Adsorbent prepared from Mango Seeds. Pacific Journal of Science and Technology 15(1):232-244.

Adegoke, H. I, Adekola, F. A., Fatoki, O. S. and Ximba, B. J. 2013. Adsorption of Cr (VI) on synthetic hematite $\left(a-\mathrm{Fe}_{2} \mathrm{O}_{3}\right)$ nanoparticles of different morphologies. Korean Journal of Chemical Engineering 31(1): 142-154.

Ahmed, F. H., Zahraa, H. and Falah, H. H. 2013. Adsorption of Disperse Blue Dye on Iraqi Date Palm Seeds Activated Carbon. International Journal of Chemical Science 11(3): 1219-1233.

Al-Haddabi, M., Ahmed, M., Al.Jebri ,Z., Hari, V., 
Znad, H. and Al.Kindi, M. 2015. Boron removal from seawater using date palm (Phoenix dactylifera) seed ash. Desalination and Water Treatment 2014(1): 1-8.

Arshad, I. E., Minerva, E. M., Hisham, A. H., Farouk, $M$ and Abdel, A. 2014. Adsorption of Heavy Metals from Industrial Wastewater using Palm Date Pits as Low Cost Adsorbent. International Journal of Engineering and Advanced Technology (IJEAT) 3(5): 71-76

Chandrasekaran, M and Bahkali, A. H. 2012. Valorization of date palm (Phoenix dactylifera) fruit processing by-products and wastes using bioprocess technology Review. Saudi Journal of Biological Sciences 20: 105-120.

Falah, H. H., Ahmed, F. H., Abbas, J. L., and Zahraa, H. A. 2015. Preparation and Characterization of Activated Carbon from Iraqi Khestawy Date Palm. Journal of Chemistry 1:1-8.

Fendorf, S., Eick, M. J., Grossl, P. and Sparks, D. L. 1997. Arsenate and Chromate Retention Mechanisms on Goethite. 1: Surface Structure. Environmental Science and Technology 31:315-320.

Guo H.B. and Barnard A.S. 2013. Naturally occurring iron oxide nanoparticles: morphology, surface chemistry and environmental stability. Journal of Materials Chemistry A1:27-42.

Harikumar, P.S., Joseph, L. and Dhanya, A. 2013. Photocatalytic degradation of textile dyes by hydrogel supported titanium dioxide nanoparticles. Journal of Environmental Engineering and Ecological Science 2: 1-9.

Lakshmipathiraj, P., Narasimhan B.R.V., Prabhakar, S. and Bhaskar Raju, G. 2006. Adsorption of arsenate on synthetic goethite from aqueous solutions, Journal of Hazardous Materials 136(2): 281-287.
Lee, G.H., Kim, S.H., Choi, B. J. and Huh, S. H. 2004. Magnetic Properties of Needle-like $\alpha-\mathrm{FeOOH}$ and $\gamma$-FeOOH Nanoparticles, Journal of the Korean Physical Society 45(4): 1019-1024.

Maji, S. K., Anjali, P., Tarasanka, P., and Asok, A. 2007. Adsorption Thermodynamics o Arsenic on Laterite soil. Journal of Surface Science and Technology 22(3-4):161-176.

Mutembei, P. K., Naftali, T. M. and Jackson, W. M. 2014. Iron Enrichments in Laterites Soils from Selected Regiond in Kenya Using Magnetic Seperation. IOSR Journal of Engineering (IOSRJEN) 4(3): 42-48.

Van der Zee, C., Roberts, D., Rancourt, D. G. and Slomp, C. P. 2003. Nanogoethite is the dominant reactive oxyhydroxide phase in lake and marine sediments. Geology 31(11): 993-996.

Villacís-García, м., Ugalde-Arzate, м., VacaEscobar, K., Villalobo-Rodolfo, M. Z. and Martínez-Villegas, N. 2015. Laboratory synthesis of goethite and ferrihydrite of controlled particle sizes. Boletin De la Sociedad Geologica Mexicana 67(3): 433-446.

Villalobos, M. and Antelo, J. 2011. A unified surface structural model for ferrihydrite: Proton charge, electrolyte binding, and arsenate adsorption. Revista Internacional de Contaminación Ambiental27:139-151.

Villalobos, M. and Perez-Gallegos, A. 2008. Goethite surface reactivity: A macroscopic investigation unifying proton, chromate, carbonate, and lead (II) adsorption. Journal of Colloid and Interface Science 326: 307-323.

Yoshiguki, S. and Yukata, K. 2003. Pyrolysis of plant, animal and human waste:physical and chemical characterization of the pyrolytic product. Bioresource Technology 90(3):241-247. 